Article

\title{
Research on the Rational Design Method of Strength Reinforcement for Thin-Walled Structure Based on Limit Load Analysis
}

\author{
Qianni Wang, Caifu Qian and Zhiwei Wu *
}

Citation: Wang, Q.; Qian, C.; Wu, Z Research on the Rational Design Method of Strength Reinforcement for Thin-Walled Structure Based on Limit Load Analysis. Appl. Sci. 2022, 12, 2208. https://doi.org/10.3390/ app12042208

Academic Editor: Motoharu Fujigaki

Received: 24 January 2022

Accepted: 18 February 2022

Published: 20 February 2022

Publisher's Note: MDPI stays neutral with regard to jurisdictional claims in published maps and institutional affiliations.

Copyright: (C) 2022 by the authors. Licensee MDPI, Basel, Switzerland. This article is an open access article distributed under the terms and conditions of the Creative Commons Attribution (CC BY) license (https:// creativecommons.org/licenses/by/ $4.0 /)$.
College of Mechanical and Electrical Engineering, Beijing University of Chemical Technology, Beijing 100029, China; wangqianniwyy@163.com (Q.W.); qiancf@mail.buct.edu.cn (C.Q.)

* Correspondence: zwzhiweiwu@163.com

\begin{abstract}
Thin-walled structures subjected to internal or external pressure usually need to be reinforced with ribs. The design of ribs is generally based on experiences in engineering, and the results are often very conservative. In this paper, an approach for the rational design of reinforced ribs on thin-walled structures is proposed based on the limit load analysis method, maximizing the limit load of the reinforced thin-walled structure or minimizing the weight of the reinforced ribs. Firstly, the limit load numerical analysis was conducted to study rib forms at the continuous and discontinuous regions of the structure and find the rational ribs which provide the most effective reinforcement for the structure. Then, using the proposed rib forms, an engine test cabin was re-designed based on the limit load analysis to verify the feasibility and effects of the rib design. The engine test cabin after the redesign of the rib plate can reach $98 \%$ of the limit load of the original test cabin while the weight of reinforcing ribs is only $62 \%$ of the weight of the original ones, which means that the reinforcement design approach based on the limit load analysis method and the rib forms proposed in this paper is effective and feasible, and can achieve a structural lightweight design.
\end{abstract}

Keywords: reinforcing rib; strength design; limit load analysis; thin-walled structure

\section{Introduction}

As they have the advantage of a light weight, reinforced thin-walled structures are widely used in aviation, shipbuilding and construction engineering [1-5]. By reinforcing ribs, the stiffness or strength of thin-walled structures could be significantly raised without increasing the weight of the whole structure by much. On the other hand, if the reinforcing ribs are not rationally arranged, the reinforcement would not be effective and thus the whole weight of the structure would not be decreased. So, the rational design of reinforcing ribs for thin-walled structures is of significance in engineering.

Various studies have been conducted on the rational design of reinforced structures. Buckling analysis and optimization by means of the finite element method (FEM) of hierarchical stiffened plates under axial compression suffer from heavy computational costs; Wang et al. [6] proposed an efficient and simple hybrid framework for the buckling analysis and optimization of hierarchical stiffened plates. Mojtaba et al. [7] found that for steel plate shear walls with a partial plate-column connection (SPSW-PC), although removing the connection between the web-plate and columns can be beneficial in terms of decreasing the overall system demand on the vertical boundary members, based on the results and findings of this research study, such detachment can reduce the stiffness and strength capacities of steel shear walls by about $25 \%$ on average.

To improve the mechanical properties of reinforced thin-walled structures, some design schemes and algorithms have been proposed [8]. Zhang et al. [9] studied two methods for the finite element analysis of stiffened plate structures and compared their calculation accuracy and efficiency. Based on the discrete finite element model of plate 
beams, the growth and removal of stiffeners were controlled by the ESO method, and a reasonable stiffener layout was obtained. The method of structural topology optimization is often used to optimize the design of the location and cross-sectional dimensions of the reinforcement for thin-walled structures. One of the earliest studies to determine the optimal reinforcement layout based on the plate thickness obtained through topology optimization to design reinforced plates was conducted by Cheng et al. [10]. Krog et al. [11] adopted a homogenization method to obtain an optimized rib layout. The obtained results did not give a clear reinforcement layout, although the optimized thickness distribution was given. Ansola et al. [12] proposed a method to simultaneously optimize the geometry of the planes in the shell and the layout of the surface stiffeners. Rais-Rohani et al. [13] determined the optimal composite reinforcement layout based on the optimized plate thickness. Lam et al. [14] proposed a strategy combining topology optimization and shape optimization to identify the optimal layout, in which the same height was used in the region with nearly the same or a higher thickness. Liu et al. [15] proposed a new Heavisidefunction-based directional growth topology parameterization (H-DGTP) of the casting constraints for simultaneously optimizing the layout and height of the stiffeners. Liu [16] proposed a topology optimization method based on Opti-Struct. By specifying the thickness of the thin-plate foundation and extending the design space along the height of the ribs, the distribution results of the material reinforcement trajectories were obtained, and then the reinforcement layout design of the thin-walled structure was guided.

The adaptive growth method and variable density method are often used in the design of stiffeners. Ding et al. [17] proposed an adaptive growth design method based on the research on the optimality of the branch system form in nature and its growth mechanism, taking the stiffener distribution design of the thin-plate structure as an example. Hu et al. [18] proposed an improved version of the adaptive growth method to solve the problem of the dynamic performance making it difficult to effectively grow stiffeners in a 3D box structure due to the effects of structural characteristics on natural frequencies. Based on the variable density topology optimization method, Cai et al. [19] carried out sensitivity analysis, used the optimal criterion method to solve the optimization model, and according to the topology optimization results, the layout of the vibrating table surface reinforcement was optimized to obtain a reasonable shaking table structure. Li et al. [20] proposed a heuristic reinforcement growth design method, where the reinforcement grows and branches from a given initial point in the direction that makes the structural performance optimal, while removing the reinforcement that contributes little to the structural performance, gradually forming an optimal reinforcement layout. Feng et al. [21] developed an effective B-spline parameterization method for the stiffener layout optimization of shell structures. Compared with the standard density-based method, the proposed method produces checkerboard-free design results with a clear layout and naturally avoids overhanging stiffeners.

However, since the topology optimization design takes the thickness [14] or density [22] of the element as the design variable, the design of the reinforcement layout on the thin plate is transformed into the distribution of the substrate material. So, there are problems such as the unclear distribution of reinforcement and uneven or discontinuous cross-section of reinforcement [23], which make application in engineering designs difficult. The objective of this paper is to propose a clear, simple and easy-to-implement approach for reinforcing the rib design of thin-walled structures based on the limit load analysis method. Different forms of reinforcing ribs with the same weight set at the continuous or discontinuous regions of the structure were studied, assessing their reinforcement effects on the limit load of the structure. Then, rational rib forms and arrangements were proposed. As an example, the approach was verified for its feasibility and effectiveness in the reinforcing rib design for an engine test module. 


\section{Analysis of Two Basic Forms of Reinforcing Ribs}

In limit load analysis, the material is considered to be elastic-perfect-plastic, or in other words, the stress-strain relationship of the material is linear in the elastic deformation stage but the tangent modulus changes to zero after yielding. ANSYS Workbench 18.0 was used to conduct the simulation study in this paper. The calculation is non-linear and the load corresponding to the sub-step before divergence, i.e., the last convergence sub-step, is the limit load. From the limit load analysis, the weak-strength area can be determined by investigating the yield zone in the stress distribution. It is generally believed that, according to the stress distribution results obtained from the limit load analysis, reinforcement should be provided at the yield zone, and the reinforcement effect will vary with different forms of reinforcing ribs. In this section, different forms of reinforcing ribs with the same weight set at the continuous or discontinuous regions of the structure were studied for their reinforcement effects on the limit load of the structure.

\subsection{At the Structural Continuity Region}

For a rectangular plate with a thickness of $20 \mathrm{~mm}$, as shown in Figure 1, under a transverse pressure load and constrained on four edges, the limit load can be easily obtained with finite element analysis. Figure 1 shows the von Mises stress distribution under the limit load. It is seen that in the central part of the plate, there is an approximately rectangular yield zone which is a weak-strength region. To increase the limit load, there are two ways to set the reinforcing ribs. One is along the direction of the long side of the yield zone, and the other is along the direction of the short side of the yield zone, as shown in Figures 2 and 3, respectively. The limit loads are calculated again with the two methods of reinforcement under the same cross-sectional shape of the reinforcing ribs having almost the same weights and the thickness of the reinforcing ribs is $20 \mathrm{~mm}$. The results for the limit loads are listed in Table 1. It is clear that with the same weight, the limit load for the ribs set along the short side of the yield zone is larger than that along the long side.

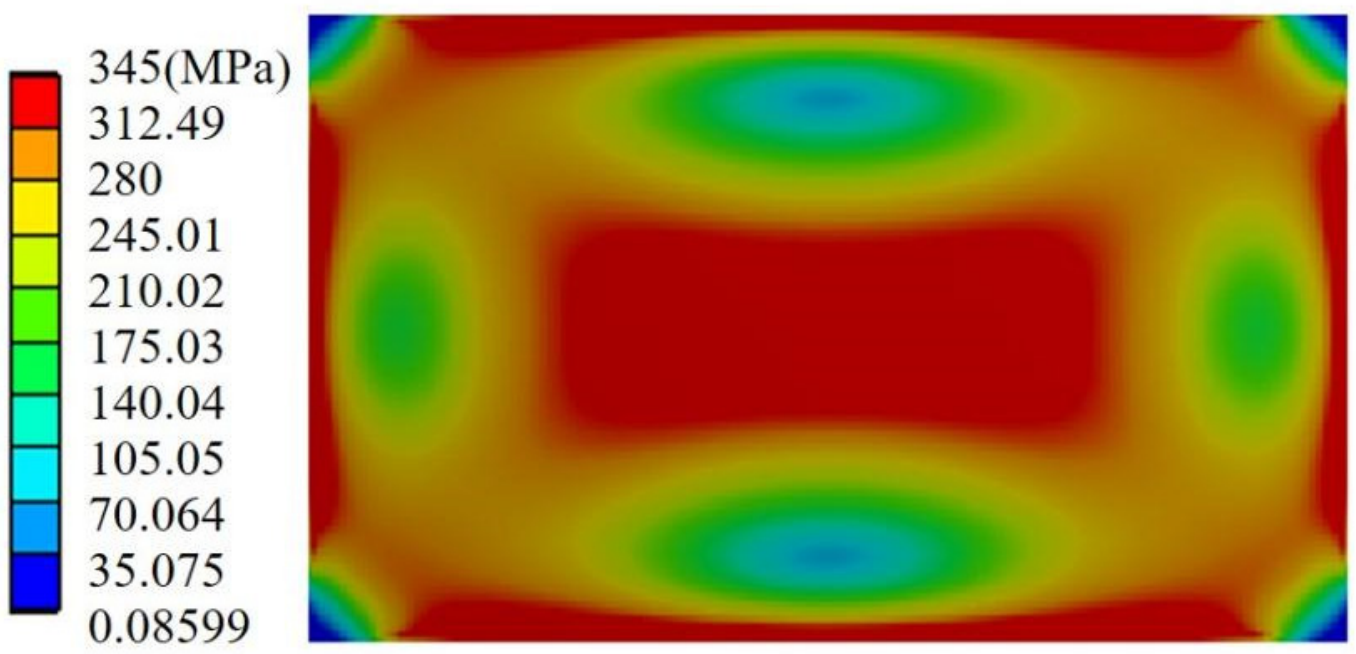

Figure 1. Contours of von Mises stress distribution on a thin plate under limit load.

Table 1. Comparison of reinforcement effects for the ribs on a plate.

\begin{tabular}{cccc}
\hline Structure & Along Long Side & Along Short Side & Short over Long \\
\hline Limit load value $(\mathrm{Mpa})$ & 0.0425 & 0.075 & Increased by $76.47 \%$ \\
Rib volume $\left(\mathrm{m}^{3}\right)$ & 0.18 & 0.18 & Same \\
\hline
\end{tabular}




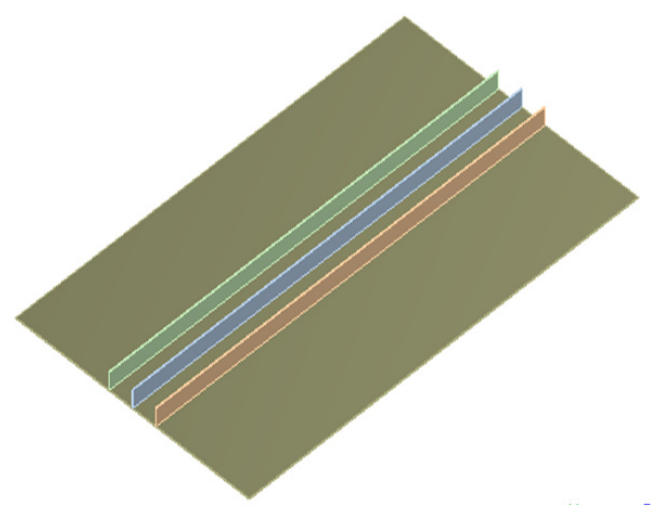

Figure 2. Illustration of the reinforcing ribs along the long side.

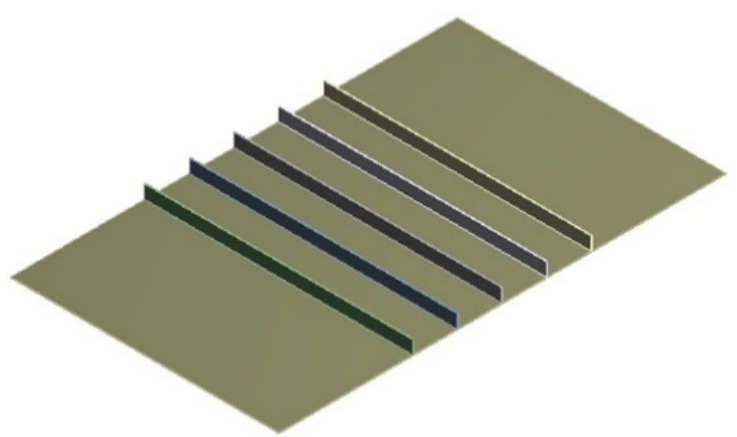

Figure 3. Illustration of the reinforcing ribs along the short side.

Therefore, for the area away from the structural discontinuity, if there is a quasirectangular or elliptical yielding zone that determines the magnitude of the limit load, a rational design would be to arrange the reinforcing ribs along the direction of the short side of the yield zone.

\subsection{At the Structural Discontinuity Region}

Structural discontinuities inevitably exist in engineering structures, and in the structural discontinuity regions often exist high stress and so they need to be reinforced. How do we design reinforcing ribs rationally? As a demonstration, Figure 4 shows a thin-walled structure composed of two flat plates. Limit load analysis was performed under the lateral pressure load on the surface of the plate, which was constrained at both ends. As shown in Figure 4, there is a long yield zone at the connection region of the flat plates. In order to increase the limit load, two forms of reinforcing ribs are proposed here. Rib form 1: as shown in Figure 5a, the same ribs with a thickness of $20 \mathrm{~mm}$ and a height of $390 \mathrm{~mm}$ are set up in the structures of the two plates and connected at the structural connection region. Figure $5 \mathrm{~b}$ shows the von Mises stress distribution after reinforcement. Obviously, the ribs play a significant role in strength reinforcement. Rib form 2: as shown in Figure 6a, based on rib form 1, a triangular plate was added to the connection area of the two ribs having a decreased height of $300 \mathrm{~mm}$ compared with the ribs in Figure 5a in order to keep the weight of the two forms of ribs the same. Figure $6 \mathrm{~b}$ shows the von Mises stress distribution after reinforcement. We kept rib form 1 and rib form 2 at the same weight and performed finite element limit load analysis, and the results of the limit loads are listed in Table 2. It can be seen that the limit load by using rib form 2 is much larger than that using rib form 1 . Therefore, in the discontinuity region, such as the connection of a tube and shell, reinforcing ribs with triangular plates are more effective to increase the load-carrying capacity of the structure. 


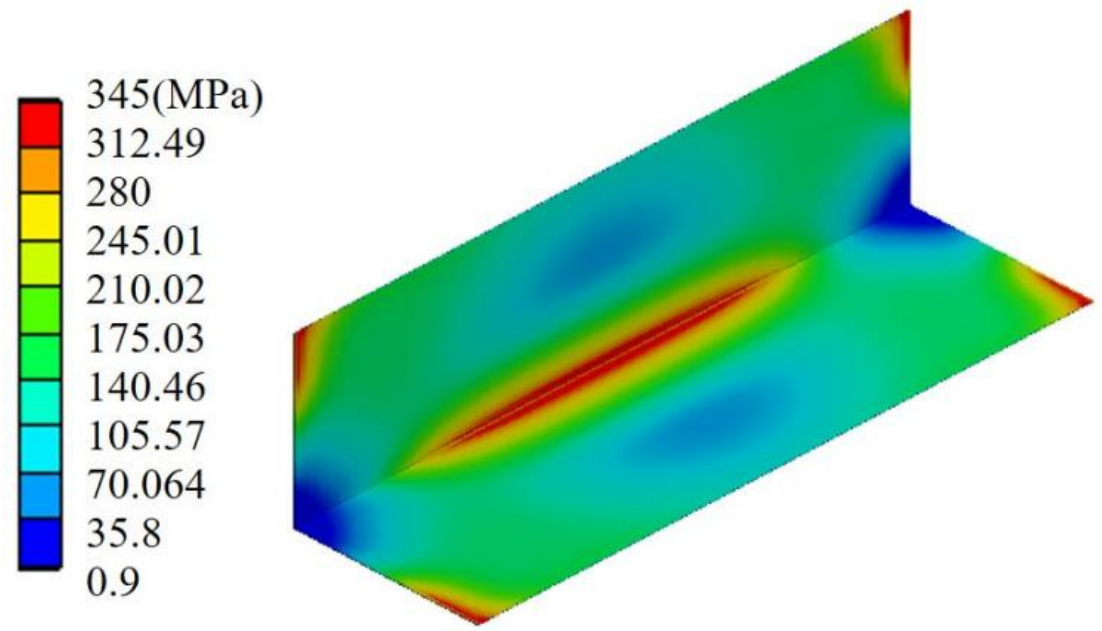

Figure 4. Contours of the von Mises stress distribution of connected plates without ribs.

(a)

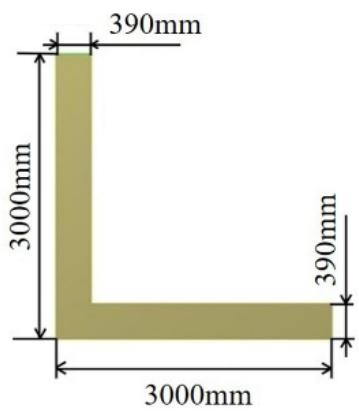

(b)

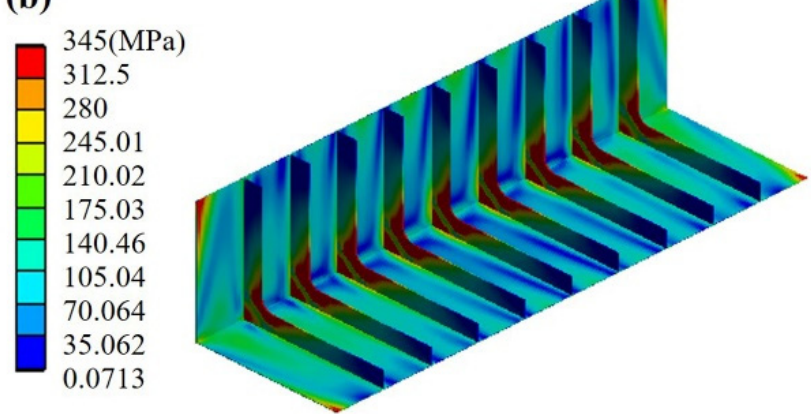

Figure 5. Contours of the von Mises stress distribution of connected plates reinforced with rib form 1 : (a) rib form 1 ; (b) contours of the von Mises stress distribution.

(a)

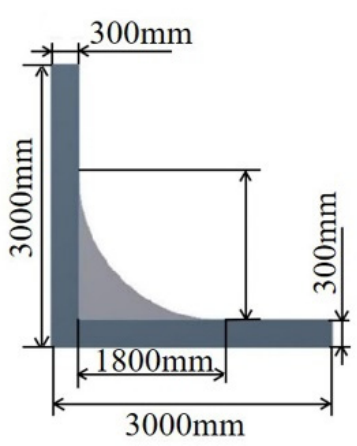

(b)

$345(\mathrm{MPa})$

312.5

280

245.04

210.07

175.11

140.14

105.18

70.064

35.248

0.2831

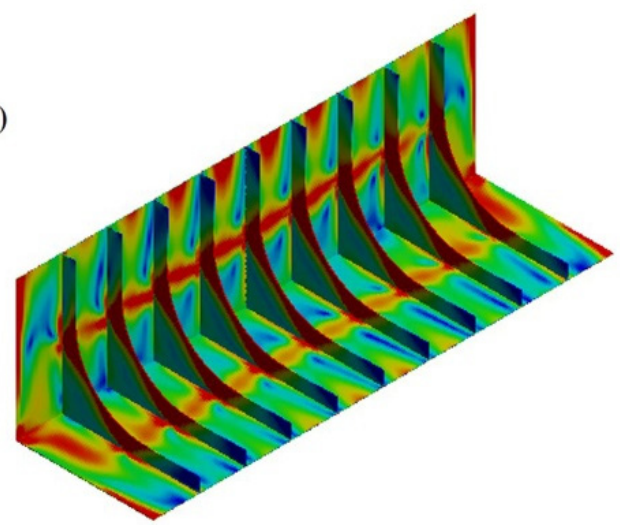

Figure 6. Contours of the von Mises stress distribution of connected plates reinforced with rib form 2: (a) rib form 2; (b) contours of the von Mises stress distribution.

Table 2. Comparison of reinforcement effects for the different ribs at structural discontinuity region.

\begin{tabular}{cccc}
\hline Structures & Rib Form 1 & Rib Form 2 & Rib Form 2 over Rib Form 1 \\
\hline Limit load value $(\mathrm{Mpa})$ & 0.198 & 0.380 & Increased by $91.91 \%$ \\
Rib volume $\left(\mathrm{m}^{3}\right)$ & 0.395 & 0.394 & Reduced by $0.25 \%$ \\
\hline
\end{tabular}




\section{Application of Rationalized Design of Reinforcing Ribs Based on Limit Analysis}

In this section, an engine test cabin is taken as an example to show a rational design of reinforcing ribs.

The engine test cabin comes from a real-world source and was originally reinforced with ribs based on experience. The reinforcing ribs of the cabin were redesigned using the reinforcement approach proposed in the previous section and compared with the original ones with the same load-bearing capacity, i.e., limit load.

The geometric model of the original design of the engine test cabin is shown in Figure 7. The length and inner diameter of the engine test cabin are $12.9 \mathrm{~m}$ and $5.705 \mathrm{~m}$, respectively. The thickness of the test cabin is $22.5 \mathrm{~mm}$. The material of all components is low alloy carbon steel Q345R with Young's modulus being $2.0 \times 10^{5} \mathrm{MPa}$ and the yield strength being $345 \mathrm{MPa}$. Under working conditions, acting loads include the pressure load, equivalent pressure load and pipeline thrust load on tubes. Figure 8 shows the load application. The pressure load and the equivalent pressure load on the tubes are applied in the same proportion when performing limit load analysis [24].

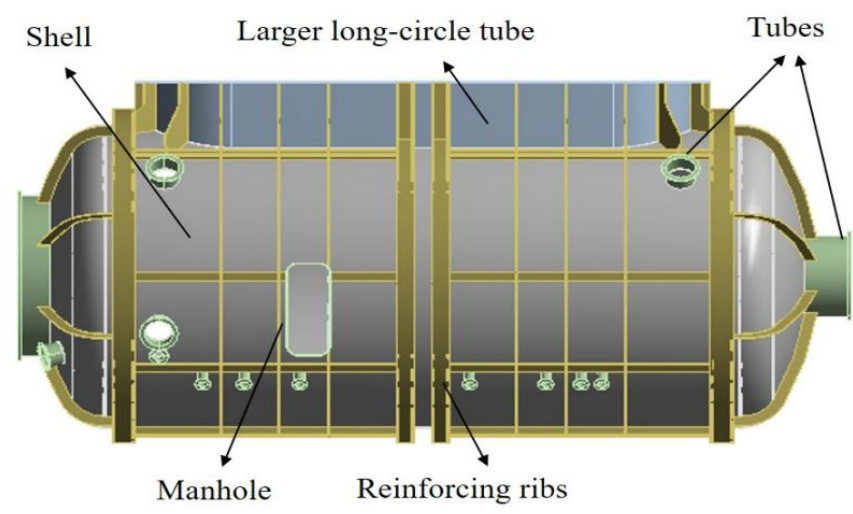

Figure 7. Illustration of the test cabin with the original reinforcing ribs.

(a)
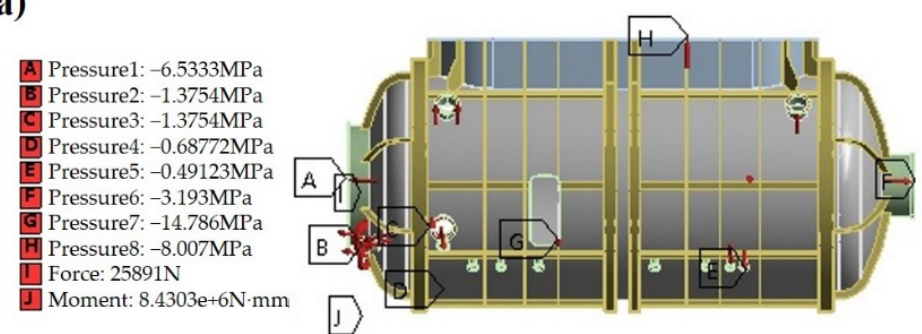

(b)

Pressure: $0.98246 \mathrm{MPa}$

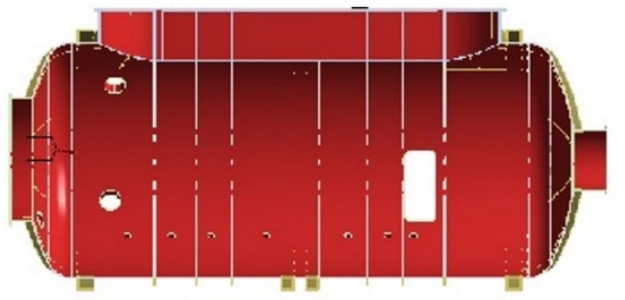

Figure 8. Illustration of load application: (a) equivalent pressure load and pipeline thrust load on tubes; (b) pressure load of the test cabin and tubes.

Firstly, the finite element limit load analysis was carried out for the test cabin shell without reinforcement. It turned out that the limit load was $0.135 \mathrm{MPa}$, and the von Mises stress distribution under the limit load is shown in Figure 9. It was seen that the yield zones appeared at the large tube, the structural discontinuity region between the shell 
and the large tube, and the region of the shell near the large tube at the top. Similarly, by performing limit load analysis on the originally reinforced test cabin as shown in Figure 7, it was found that the limit load was 0.296 MPa.

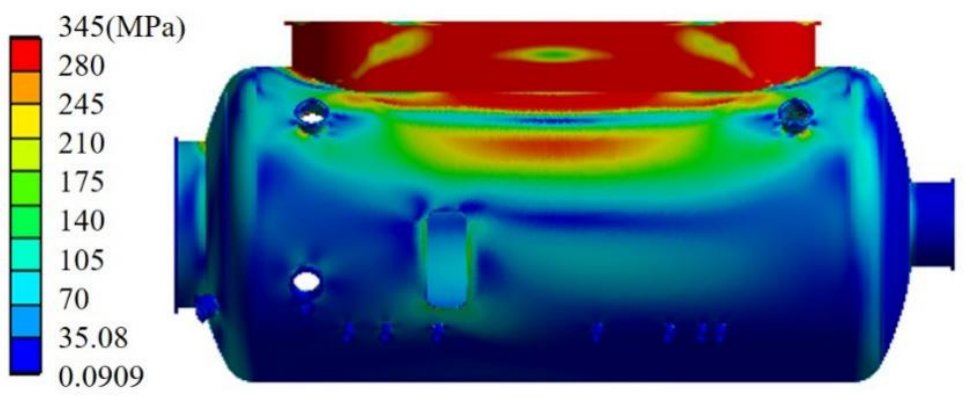

Figure 9. Contours of the von Mises stress distribution of the test cabin without reinforcement ribs under limit load.

In Figure 9, the yield zone at the connection area between the large tube and the test cabin shell is elongated, and an elongated yield zone is also found on the test cabin shell away from the connection region. Therefore, according to the approach for setting up the ribs in the previous section, the most effective ribs should be rib form 2 and arranged circumferentially, as shown in Figure 10, and the dimensions of the ribs are shown in Figure 10a. By performing limit load analysis, the limit load with a comparison of that of the original test cabin is listed in Table 3. It can be seen that by applying the rib design approach in this paper, the limit load is close to $86 \%$ of the limit load of the original design by using only half the weight of ribs. Figure 11 shows the von Mises stress distribution of the test cabin under the limit load where only the circumferential ribs of rib form 2 are applied.

(a)

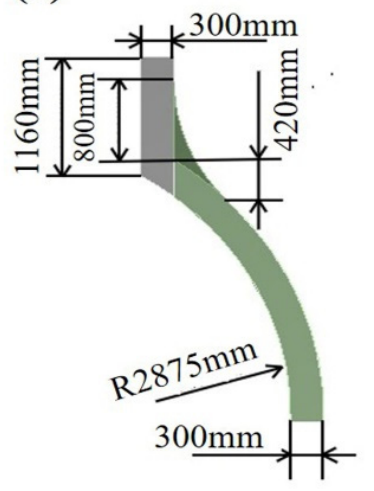

(b)

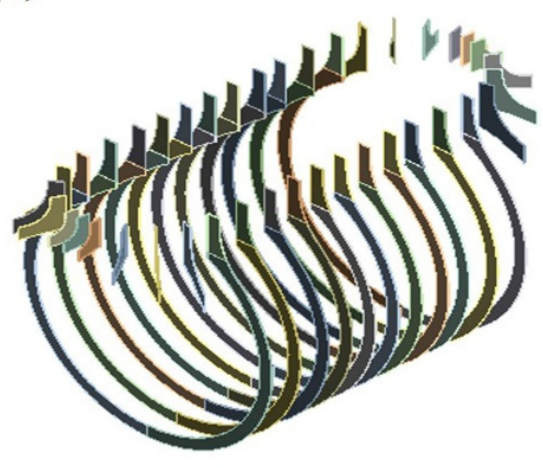

(c)

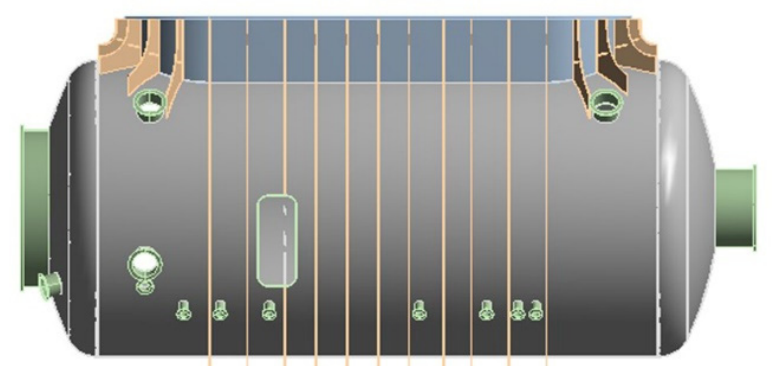

Figure 10. Reinforcing ribs and the reinforced test cabin: (a) reinforcing ribs; (b) arrangement of reinforcing ribs; (c) reinforced test cabin. 
Table 3. Comparison of the effect of the rationalized design of the ribs.

\begin{tabular}{cccc}
\hline Structure & Original Reinforced Cabin & Present Reinforced Cabin & Present over Original \\
\hline Limit load value $(\mathrm{Mpa})$ & 0.296 & 0.254 & $85.81 \%$ \\
Stiffener volume $\left(\mathrm{m}^{3}\right)$ & 2.626 & 1.364 & $51.92 \%$ \\
\hline
\end{tabular}
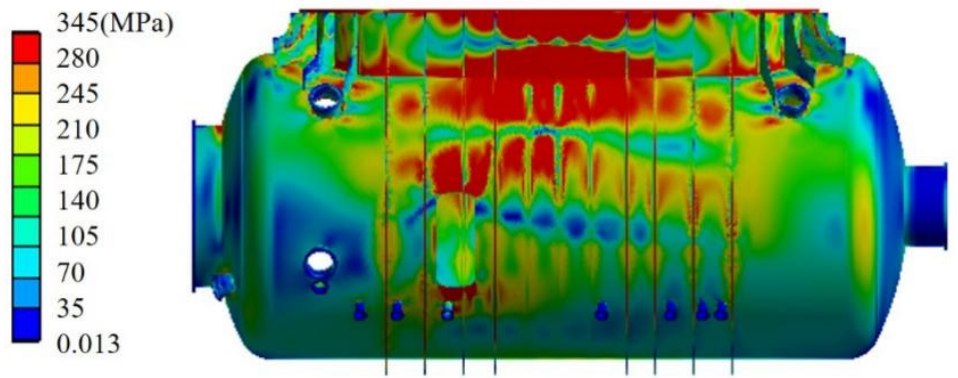

Figure 11. Contours of the von Mises stress distribution of the test cabin under the limit load after the circumferential ribs are applied.

As seen in Figure 11, the yield zone was separated by the circumferential reinforcing ribs, although it was still concentrated in the upper region of the cabin. At this time, in order to increase the load-carrying capacity, axial (or transverse) reinforcing ribs should be chosen for local strengthening. Similarly, by performing limit analysis, it was found that T-ribs are more effective, as shown in Figure 12. Figure 13 shows the test cabin reinforced by both the longitudinal and transverse ribs. A finite element limit load analysis was again performed, and the von Mises stress distribution of the test cabin under the limit load is shown in Figure 14 and the limit load with a comparison of that of the original test cabin is listed in Table 4. It was found that the limit load was $0.289 \mathrm{MPa}$, reaching $98 \%$ of the limit load of the original test cabin, while the weight of the reinforcing ribs was only $64 \%$ of the weight of the original ones. Therefore, the reinforcement design approach based on limit load analysis and the proposed rib forms presented in this paper is effective and feasible in the lightweight design of thin-walled structures.

(a)

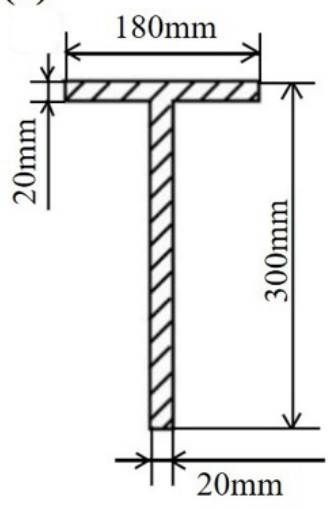

(b)

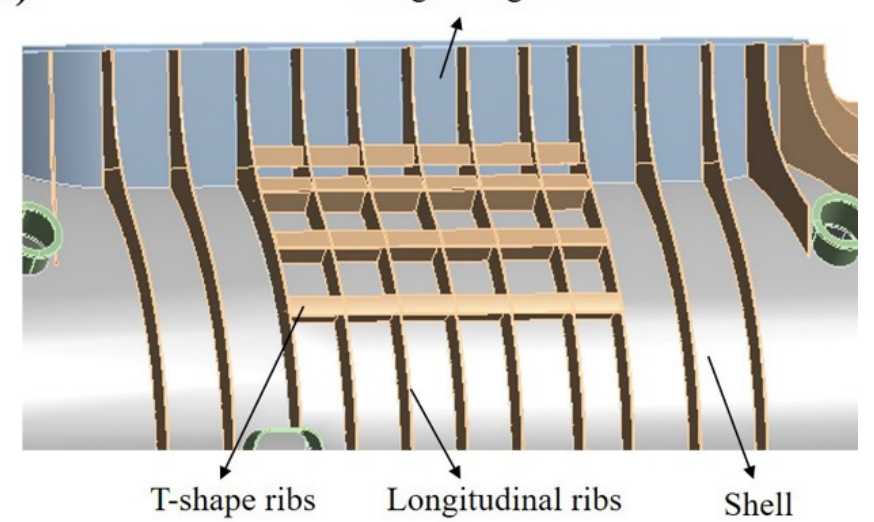

Figure 12. T-ribs and reinforcement: (a) T-ribs; (b) T-rib reinforcement.

Table 4. Comparison of the reinforcement effects with different reinforcing ribs.

\begin{tabular}{cccc}
\hline Structure & Original Reinforced Cabin & Present Reinforced Cabin & Present over Original \\
\hline Limit load value $(\mathrm{Mpa})$ & 0.296 & 0.289 & $97.63 \%$ \\
Stiffener volume $\left(\mathrm{m}^{3}\right)$ & 2.626 & 1.364 & $63.76 \%$ \\
\hline
\end{tabular}




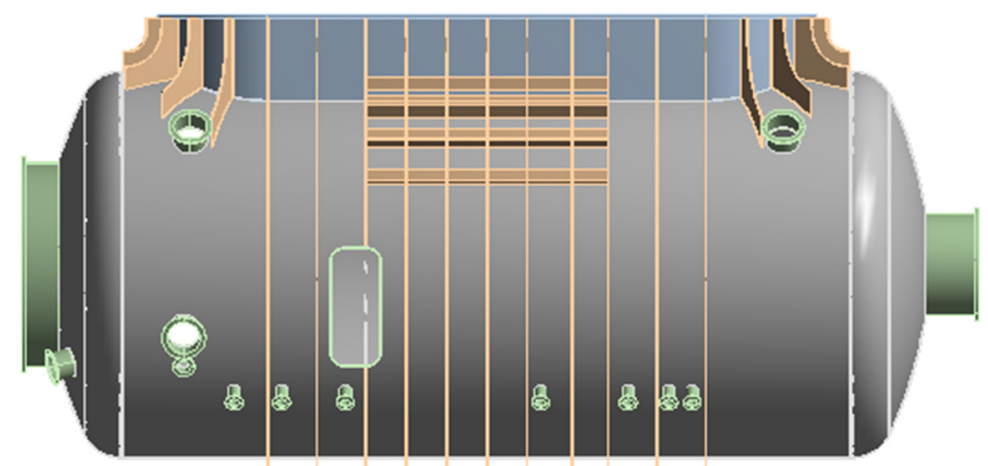

Figure 13. Illustration of the test cabin reinforced with longitudinal and transverse ribs.
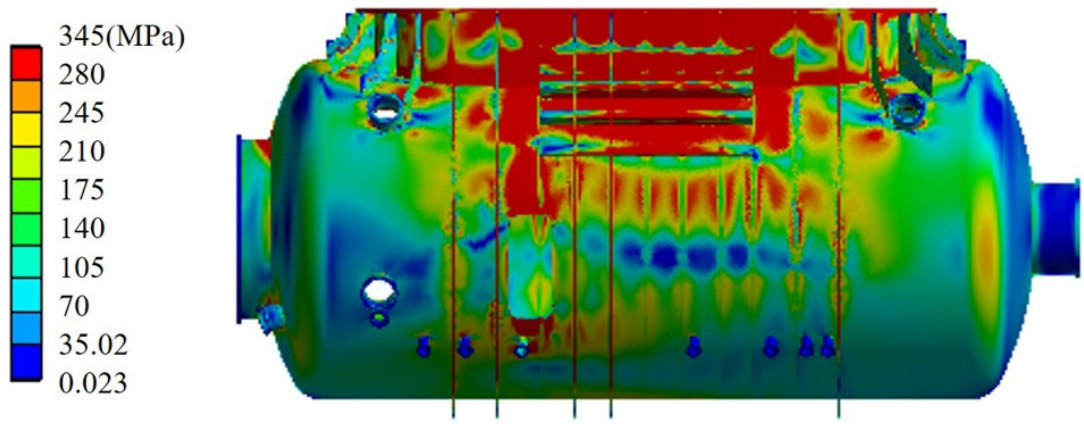

Figure 14. Contours of the von Mises stress distribution of the test cabin under the limit load after the T-ribs are applied.

\section{Conclusions and Discussions}

In this paper, a simple and practical approach for the rational strength reinforcement of thin-walled structures was studied. Conclusions were drawn as follows:

(1) By performing limit load analysis, the yield zone or weak-strength zone together with the shape can be easily found and thus, reinforcing ribs can be effectively placed.

(2) For the region away from the structural discontinuity, if the yield zone under the limit load is quasi-rectangular or elliptical, the rational arrangements of the reinforcing ribs should be along the short side of the yield zone.

(3) In the discontinuity area, the reinforcing rib with a triangular plate is more effective to reinforce the strength of the structure.

(4) The application of the reinforcement to improve the strength of an engine test cabin found that, after the redesign of the rib plate, the engine test cabin can reach $98 \%$ of the limit load of the original test cabin, while the weight of reinforcing ribs is only $62 \%$ of the weight of the original ones, implying that the reinforcement design approach based on limit load analysis and proposed rib forms presented in this paper is effective and feasible for the lightweight design of thin-walled structures.

It is noted that compared with the stress classification method, the limit load method is relatively simple and reliable. As the reinforced structures are generally complicated, it is difficult to achieve a lightweight design using the stress classification method. However, the approach proposed in this paper is feasible, and the design efficiency is high. By finding the yield zone or the weak-strength zone, reinforcement ribs can be put in the most effective places so that the whole structure can be lightweight, which is hard to achieve using other methods.

In addition, the reinforcement design method proposed in this paper is useful for improving the strength of structures. In engineering, more reinforced structures are subjected to external pressure, and the reinforcing ribs increase the rigidity of the structures. For the 
problem of external pressure instability, the authors believe that the same approach can be adopted, but the limit load analysis should be changed to stability analysis, the limit load should be changed to the critical load, and the design of reinforcement should be related to the instability modes.

Author Contributions: Conceptualization, C.Q.; methodology, C.Q.; software, Q.W. and Z.W.; validation, Q.W., and Z.W.; formal analysis, Q.W.; investigation, Q.W.; resources, C.Q.; data curation, Q.W.; writing —original draft preparation, Q.W.; writing — review and editing, C.Q. and Z.W.; visualization, C.Q.; supervision, C.Q.; project administration, C.Q.; funding acquisition, C.Q. All authors have read and agreed to the published version of the manuscript.

Funding: This research received no external funding.

Institutional Review Board Statement: Not applicable.

Informed Consent Statement: Not applicable.

Data Availability Statement: Data available on request.

Conflicts of Interest: The authors declare no conflict of interest.

\section{References}

1. Sun, Y.; Zhou, Y.; Ke, Z.; Tian, K.; Wang, B. Stiffener layout optimization framework by isogeometric analysis-based stiffness spreading method. Comput. Methods Appl. Mech. Eng. 2021, 390, 114348. [CrossRef]

2. Putra, G.L.; Kitamura, M.; Takezawa, A. Structural optimization of stiffener layout for stiffened plate using hybrid GA. Int. J. Nav. Archit. Ocean Eng. 2019, 11, 809-818. [CrossRef]

3. Chen, F.; Zhu, J.; Du, X.; Zhang, R.; Zhang, W. Shape preserving topology optimization for structural radar cross section control. Chin. J. Aeronaut. 2021; in press. [CrossRef]

4. Liu, Z.; Cho, S.; Takezawa, A.; Zhang, X.; Kitamura, M. Two-stage layout-size optimization method for prow stiffeners. Int. J. Nav. Archit. Ocean Eng. 2019, 11, 44-51. [CrossRef]

5. Zhou, L.; Sigmund, O.; Zhang, W. Self-supporting structure design with feature-driven optimization approach for additive manufacturing. Comput. Methods Appl. Mech. Eng. 2021, 386, 114110. [CrossRef]

6. Wang, B.; Tian, K.; Hao, P.; Cai, Y.; Li, Y.; Sun, Y. Hybrid analysis and optimization of hierarchical stiffened plates based on asymptotic homogenization method. Compos. Struct. 2015, 135, 136-147. [CrossRef]

7. Mojtaba, G.A.; Ali, M.R.; Masoud, M.; Maria, R.; Hamid, A. Numerical and analytical study of ultimate capacity of steel plate shear walls with partial plate-column connection (SPSW-PC). Structures 2021, 33, 3038-3066. [CrossRef]

8. Wang, D.; Li, Z. Layout optimization method for stiffeners of plate structure. Chin. J. Comput. Mech. 2018, 35, 138-143. (In Chinese)

9. Zhang, S.; Yang, J.; Zhang, W. Evolutionary structural optimization for stiffener layout problem of plate structures. Morden Manuf. Eng. 2009, 4, 5-9. [CrossRef]

10. Cheng, K.T.; Olhoff, N. Investigation concerning optimal design of solid elastic plates. Int. J. Solids Struct. 1981, 3, 305-323. [CrossRef]

11. Krog, L.A.; Olhof, N. Optimum topology and reinforcement design of disk and plate structures with multiple stifness and eigenfrequency objectives. Comput. Struct. 1999, 72, 535-563. [CrossRef]

12. Ansola, R.; Canales, J.; Tarrago, J.A.; Rasmussen, J. Combined shape and reinforcement layout optimization of shell structures. Struct. Multidisc. Optim. 2004, 27, 219-227. [CrossRef]

13. Rais-Rohani, M.; Lokits, J. Reinforcement layout and sizing optimization of composite submarine sail structures. Struct. Multidiscip. Optim. 2007, 34, 75-90. [CrossRef]

14. Lam, Y.C.; Santhikumar, S. Automated rib location and optimization for plate structures. Struct. Multidiscip. Optim. 2003, 25, 35-45. [CrossRef]

15. Liu, S.; Li, Q.; Chen, W.; Hu, R.; Tong, L. H-DGTP-A Heaviside-function based directional growth topology parameterization for design optimization of stiffener layout and height of thin-walled structures. Struct. Multidiscip. Optim. 2015, 52, 903-913. [CrossRef]

16. Liu, S. Topology optimization design of thin-walled stiffened structure. Sci. Technol. 2021, 2, 98-99. (In Chinese)

17. Ding, X.; Li, G.; Cai, G. The self-adaptive growth design method of stiffener for thin plate structure. China Mech. Eng. 2005, 16, 1057-1060. (In Chinese)

18. Hu, T.; Ding, X.; Shen, L.; Zhang, H. Improved adaptive growth method of stiffeners for three-dimensional box structures with respect to natural frequencies. Comput. Struct. 2020, 239, 106330. [CrossRef]

19. Cai, A.; Yang, Q. Optimization of the layout of vibration stiffeners on a flat die table based on variable density method. Chin. J. Comput. Mech. 2021, 38, 66-72. (In Chinese)

20. Li, L.; Zhang, B.; Li, Q. Optimization design of stiffener layout of thin plate structure based on sensitivity number. China Mech. Eng. 2016, 27, 1143-1149. (In Chinese) 
21. Feng, S.; Zhang, W.; Meng, L.; Xu, Z.; Chen, L. Stiffener layout optimization of shell structures with B-spline parameterization method. Struct. Multidiscip. Optim. 2021, 63, 2637-2651. [CrossRef]

22. Liu, Y.; Shimoda, M. Non-parametric shape optimizaion method for natural vibration design of stiffened shell. Comput. Struct. 2015, 146, 20-31. [CrossRef]

23. Afonso, S.M.B.; Sienz, J.; Belblidia, F. Structural optimization strategies for simple and integrally stiffened plates and shells. Eng. Comput. 2005, 22, 429-452. [CrossRef]

24. Lu, M.; Shou, B.; Yang, B. Plastic analysis method for pressure vessel analysis and design. Press. Vessel. $2011,28,33-39$. (In Chinese) 